\title{
DEPOIS DO BOOM: O PIONEIRISMO DE EMPRESAS DO RAMO VAREJISTA BRASILEIRO NA ADOÇÃO DE COMÉRCIO ELETRÔNICO ${ }^{1}$
}

\section{AFTER THE e-COMMERCE BOOM: THE PIONEERS OF BRAZILIAN RETAIL ENTERPRISES}

\author{
Marie Anne Macadar ${ }^{2}$ \\ Éverton Luís Pellizzaro de Lorenzi Cancellier ${ }^{3}$ \\ Grace Vieira Becker ${ }^{4}$
}

RESUMO: Com o olhar no presente, analisa-se o pioneirismo de empresas do ramo varejista brasileiro na incorporação de atividades de Comércio Eletrônico (CE) às operações existentes. Neste sentido, são investigados os seguintes aspectos: a evolução dos negócios virtuais, as novas estruturas organizacionais criadas para apoiar as atividades de CE, os impactos exercidos por estas atividades na estrutura organizacional dos casos estudados e a posição das empresas diante de modelos de análise e compreensão dos negócios virtuais. Erros e acertos, avanços e retrocessos são discutidos com base em três estudos de caso realizados e analisados sob o foco de dois modelos teóricos. Constata-se que o principal desafio ainda continua sendo o de transformar "bits" em "átomos".

PALAVRAS-CHAVE: Comércio Eletrônico; pioneirismo; varejo; estratégia

ABSTRACT: Under the eyes of the present, this paper analyzes the pioneerism of Brazilian retail enterprises in the incorporation of e-commerce to existent activities. The following aspects are researched: the evolution of virtual businesses, the new organizational structure created to support the ecommerce activities, the impacts on the organization structure generated by these activities in the study cases and the enterprise position in front of virtual business analysis and comprehension models. The right and wrong ways, advances and retrocession are discussed based on three study cases which are analyzed under two theoretical models. It could be observed that the main difficulty still remains how to transform "bits" in "atoms".

KEY WORDS: e-Commerce; pioneers; retail; strategy

\footnotetext{
${ }^{1}$ Artigo Recebido em 18.10.2008. Revisado por pares em 30.04.2009. Recomendado em 16.10.2009 por Leomar dos Santos (Editor Adjunto). Publicado em 18.12.2009.

Organização Responsável pelo periódico: Universidade regional de Blumenau - FURB - www.furb.br/rn
}

\footnotetext{
${ }^{2}$ Universidade Estadual do Rio Grande do Sul - macadar@via-rs.net

${ }^{3}$ Universidade do Vale do Itajaí - everton@univali.br

${ }^{4}$ Pontifícia Universidade Católica do Rio Grande do Sul - grace.becker@pucrs.br
} 


\section{INTRODUÇÃO}

Não se discute mais se o Comércio Eletrônico (e-Commerce - CE) representa um dentre tantos modismos que se inserem no meio empresarial, ele veio para ficar e os números têm demonstrado explicitamente este fato. No Brasil, pesquisa do E-BIT (2006c) indicou em 2006 a presença de sete milhões de e-consumidores e vendas de $\mathrm{R} \$ 4,4$ bilhões pela Internet, um crescimento de $76 \%$ em relação a 2005 e de $700 \%$ em relação a 2001. Nos EUA as vendas pela Internet, excluindo viagens, alcançaram US\$ 102,1 bilhões em 2006 , um crescimento de $24 \%$ em relação ao ano anterior.

Muito embora as estatísticas apontem a consolidação do CE no mundo dos negócios, é importante ressaltar os vários desafios enfrentados na sua trajetória de desenvolvimento. Os pioneiros desta nova modalidade de realizar transações comerciais passaram certas dificuldades e muitos tiveram que encerrar suas atividades bem antes do que imaginavam. No final da década de 90, “... empreendedores alugavam garagens sem saber exatamente o que vender pela Internet, mas convictos de que empresas de Internet deviam começar numa garagem” (PERSONA, 2006, p.1).

Praticamente oito anos se passaram do boom das ponto.com. Algumas sobreviveram à queda da NASDAQ e ao fim da euforia e chegou o momento destes novos empreendimentos gerarem lucratividade e, principalmente, adquirirem a capacidade de auto-sustentabilidade (MYER, 2000). Assim, desvendar a estratégia na adoção de CE em empresas tanto genuinamente virtuais quanto em mistas ou tradicionais que se aventuram no mundo digital, continua sendo um grande desafio para seus gestores. Este desafio se configura desde a primeira geração de negócios, que consiste basicamente na abertura e colocação em funcionamento de sites informativos, até as mais arrojadas práticas de CE verificadas atualmente. Enquanto os sistemas de informação, armazenamento e transporte de dados parecem estar bem dominados pelos técnicos da área, o desenho de unidades digitais permanece ainda pouco explorado, especialmente quando se faz necessário adequar e ajustar estruturas tradicionais já existentes com outras voltadas para atividades em negócios virtuais. Tendo em vista este cenário, o objetivo deste estudo é analisar o pioneirismo de empresas do ramo varejista brasileiro na incorporação de atividades de Comércio Eletrônico.

A importância deste estudo não se dá exclusivamente pelo destaque que o CE vem conquistando nos últimos anos, mas principalmente pela possibilidade de analisarem-se fatos passados com o olhar no presente. O período analisado, quando o $\mathrm{CE}$ ainda era considerado uma panacéia, permite uma análise mais criteriosa e rica da trajetória pioneira destes empreendedores. Trazer à tona seus erros e acertos, avanços e retrocessos, com base no que se sabe hoje sobre CE, fornece um aprendizado que tem como base um arcabouço de conhecimentos que teria sido difícil de ser construído naquele momento.

Adotando a metodologia de estudo de casos múltiplos, este trabalho apresenta o esforço de três empresas brasileiras, uma de médio e duas de grande porte, na adoção de estruturas organizacionais voltadas para negócios virtuais. Duas atuam no varejo supermercadista e uma no setor livreiro, todas já possuindo longa experiência na realização de negócios tradicionais. $\mathrm{O}$ ponto de união destes casos consiste na decisão destas empresas de incorporarem e desenvolverem atividades de transações eletrônicas, diretamente com o consumidor (B2C), a 
partir de meados dos anos de 1990. Assim, são investigados os seguintes aspectos: a evolução dos negócios virtuais nestas empresas, as novas estruturas organizacionais criadas para suportar a emergente atividade de $\mathrm{CE}$, os impactos exercidos por esta atividade na estrutura geral dos casos estudados e a posição das empresas diante de modelos de análise e compreensão dos negócios virtuais.

O artigo está estruturado da seguinte forma: as duas primeiras seções tratam do CE e dos modelos para analisar os casos estudados. A quarta trata da metodologia empregada e a quinta da apresentação dos casos propriamente ditos. Através das lentes teóricas escolhidas, procede-se na sexta seção à análise dos casos e, na seguinte, os principais desafios e oportunidades enfrentados pelas empresas. Por fim, na oitava seção, apresentam-se as considerações finais.

\section{COMÉRCIO ELETRÔNICO}

A partir da difusão da utilização da Internet nos anos 1990, surge o termo Comércio Eletrônico (CE). Embora já se trate de uma realidade desde o início dos anos 70, é através da disseminação da Internet que o CE obtém um ambiente propício para seu desenvolvimento, especialmente pelas diversas funcionalidades disponíveis, sua plataforma aberta e seu custo acessível.

Apesar de alguns autores diferenciarem o conceito de Comércio Eletrônico e Negócios Eletrônicos (e-Business), estes termos muitas vezes são confundidos ou utilizados de forma equivalente. KALAKOTA e ROBINSON (2001) estabelecem uma diferenciação entre eles, atribuindo ao e-Business um escopo mais abrangente que ao CE. Para eles, o e-Business envolve toda a infra-estrutura, desenho de negócio e planejamento das ações necessárias para atingir as novas expectativas e necessidades dos clientes, envolvendo inclusive o CE. Além disso, o eBusiness contempla aspectos intra e interorganizacionais necessários para a sua realização. Nessa mesma linha, TURBAN et al. (1999) incluem no e-Business não só a compra e venda, mas também serviços aos consumidores e colaboração entre parceiros de negócio, incluindo transações eletrônicas entre organizações. Segundo estes autores, diversos são os tipos de transações possíveis: $B 2 B, B 2 C, C 2 C, C E$ Nonbusiness e Intraorganizacional.

Comércio Eletrônico Business-to-business (B2B) - Representa o maior volume de transações na Internet na atualidade. Envolve transações eletrônicas entre organizações.

Comércio Eletrônico Business-to-Consumer (B2C) - Envolve transações de varejo com compradores individuais.

Comércio Eletrônico Consumer-to-Consumer (C2C) - Envolve consumidores vendendo diretamente a outros consumidores.

Comércio Eletrônico Consumer-to-Business (C2B) - Inclui indivíduos que realizam transações de negócios com organizações.

Comércio Eletrônico "Nonbusiness" - Inclui interações entre organizações sem fins lucrativos, instituições de ensino, organizações religiosas, sociais e governamentais que utilizam o Comércio Eletrônico como forma de melhorar sua atuação.

Comércio Eletrônico Intra-organizacional - Inclui todas as atividades intraorganizacionais, normalmente executadas via Intranets. 
Apesar de não ser o foco deste artigo, não se deve deixar de mencionar outras formas de relacionamento eletrônico ligadas ao estudo de e-Government (e-Gov): Government-toConsumer (G2B); Government-to-Business (G2B) e Government-to-Government (G2G) (CHAHIN et al. 2004; FERRER e SANTOS, 2004). Apesar da grande diversidade de siglas, percebese que o foco dos conceitos é sempre o mesmo: a realização de negócios eletronicamente. Segundo BRANSKI (2000), sob uma perspectiva mais ampla, o CE é a "partilha de informações, manutenção de relacionamentos e condução de transações de negócios por meio de redes de telecomunicações dentro e fora das organizações". Mais especificamente, e atendendo ao escopo deste trabalho, trataremos o CE como uma atividade conduzida on-line para gerar e administrar o processo de venda e pós-venda de produtos ou serviços.

\subsection{Modelos Para Análise de Negócios Eletrônicos}

A expansão dos negócios virtuais e a criação de empresas "ponto.com" têm ocorrido em velocidade exponencial. Ao lado das empresas exclusivamente digitais, um grande número de empresas tradicionais tem engrossado estas fileiras como forma de fortalecer seus negócios. De modo a perceber melhor este fenômeno, modelos de análise e compreensão dos negócios virtuais têm sido levantados pela literatura da área.

PORTER (2001) contribui para a análise do CE ao ressaltar a importância da Internet na configuração de estratégias organizacionais. $\mathrm{O}$ autor argumenta que as empresas vencedoras serão as que usarão a Internet como um complemento à maneira tradicional de competir, ao invés de empresas que consideram suas iniciativas virtuais como algo apartado de seus negócios.

A Internet influencia a estrutura industrial por provocar mudanças e alterações nas forças competitivas que determinam a atratividade de uma indústria. Nesse mesmo artigo o autor salienta que a Internet tem criado algumas novas indústrias, mas que seu maior impacto está na capacidade de reconfigurar mercados existentes, especialmente os afetados pelos altos custos de comunicação e de realização de transações. O modelo das cinco forças competitivas para analisar a Internet (PORTER, 2001) foi traduzido e adaptado por VASCONCELlOS e MURITIBA (2005c, p.54-55) conforme segue:

- Barreiras à entrada: a Internet reduz a necessidade de força de vendas; porém, é difícil manter a propriedade das aplicações utilizadas nos sites; existem muitos concorrentes entrando em muitas indústrias, devido à facilidade de se estabelecer um site;

- Fornecedores: a Internet auxilia as empresas que compram a aumentar seu poder de barganha com seus fornecedores, embora, ao mesmo tempo, seus fornecedores passem a ter um mercado maior quando se utiliza a Internet; pode haver também uma diminuição na cadeia de produção, já que produtores podem atingir diretamente seus consumidores, sem haver necessidade de um canal de distribuição.

- $\quad$ Rivalidade entre concorrentes: reduz as diferenças entre os concorrentes e, assim, a competição se estabelece ao nível do preço; aumenta o leque de mercado, e isto torna maior o número de concorrentes das empresas; empresas virtuais têm seus custos variáveis aumentados com relação ao custo fixo, o que facilita o gerenciamento de custos; 
- Produtos substitutos: ao fazer a indústria em geral mais eficiente, a Internet aumenta o tamanho do mercado; assim há novas ameaças de produtos e serviços substitutos;

- Clientes: a Internet aumenta o poder de barganha dos clientes e também dos consumidores finais.

O segundo modelo que subsidia a análise do presente estudo é proposto por VASCONCELLOS e seus colegas (2004; 2005a; 2005b; 2005c). Este modelo é elaborado com base em extenso estudo sobre estruturas organizacionais que buscam formas de se diferenciar competitivamente em negócios eletrônicos. Segundo os autores, é possível realizar análises organizacionais em empresas que utilizam o comércio eletrônico, baseado nos níveis de compartilhamento da infra-estrutura de apoio entre a empresa tradicional e a unidade virtual. Para tanto, eles definiram níveis de compartilhamento da área de CE, escalonados de (1) a (4), sendo que, quanto maior o grau, mais compartilhado está o negócio eletrônico em relação à estrutura organizacional já existente. O modelo dos autores é apresentado a seguir:

Nível 1 - As estruturas dos negócios virtuais e tradicionais são totalmente separadas. Não há nenhum compartilhamento de recursos de infra-estrutura. Estes recursos são duplicados. Este nível foi colocado como indicação de extremidade. Trata o negócio eletrônico como se ele não tivesse nenhuma ligação com a empresa que o está criando. Este nível acontece quando a empresa cria outra empresa ou unidade estratégica separada de sua estrutura, mas sem nenhuma relação, ou seja, sem compartilhar nenhum recurso. Assim, a estrutura é toda duplicada.

Nível 2 - O negócio eletrônico é estabelecido como uma unidade separada, mas alguns recursos de infra-estrutura são compartilhados e outros são duplicados.

Nível 3 - O negócio eletrônico é estabelecido como uma unidade separada. Muitos recursos de infra-estrutura são compartilhados. É estabelecida uma diretoria para o negócio eletrônico, mas há elevado nível de compartilhamento de recursos e quase nenhuma área de infra-estrutura é duplicada.

Nível 4 - O negócio eletrônico é estabelecido como uma unidade separada. Há uma coordenação, mas todos os recursos de infra-estrutura são compartilhados. Não há duplicações.

Com base nestes dois modelos, aqui considerados complementares, realiza-se a análise dos três estudos de caso.

\section{METODOLOGIA}

O método de pesquisa utilizado é o Estudo de Casos Múltiplos (YIN, 1994), de natureza qualitativa e caráter exploratório. Este método normalmente é utilizado em situações em que o conhecimento é muito reduzido (SELLTIZ et al., 1974). O presente estudo concentra-se na análise de três empresas do setor de varejo que implantaram o comércio eletrônico. Para YIN (1994), o objetivo principal do estudo de caso, como tipo de pesquisa, é analisar intensivamente uma dada unidade social, aprofundando a descrição de um determinado fenômeno.

A partir desta ótica, procura-se identificar, descrever e analisar aspectos relacionados à utilização de práticas de CE em três empresas do setor de varejo, realizando um contraponto 
entre o mundo real e o virtual. Para manter o sigilo das informações, as unidades investigadas são denominadas de Empresas "A", "B" e "C".

A pesquisa dividiu-se em três etapas em cada uma das organizações analisadas. A primeira consistiu em entrevistas com as gerências das unidades que administraram o negócio virtual. As entrevistas pessoais seguiram um roteiro de perguntas semi-estruturadas, respeitando os limites do assunto em análise. O conteúdo das verbalizações foi gravado para assegurar o resgate e a fidedignidade das informações. A segunda parte da pesquisa consistiu na observação pessoal do pesquisador sobre todo o processo (desde o acesso ao site, elaboração da lista de compras até a entrega do produto), tendo como objetivo perceber in loco as peculiaridades dos serviços das empresas e foram realizadas em 2001, ou seja, a época em fenômeno estava em voga. A última parte da pesquisa residiu na análise de documentos fornecidos pelas empresas e em fontes públicas, tais como jornais, revistas e Internet. Essa diversidade de técnicas possibilitou a triangulação dos dados e maior confiabilidade na interpretação e análise.

\section{APRESENTAÇÃO DOS CASOS}

Esta seção apresenta os três casos de empresas varejistas estudados. A Empresa A faz parte do Grupo Supermercadista $X$, de grande porte, com unidades localizadas em diversos estados brasileiros. A Empresa B, de médio porte, apesar de atuar no mesmo setor, possui uma única loja, atingindo primordialmente seu entorno. Já a Empresa $\mathrm{C}$ faz parte de uma grande rede de livrarias, com mais de 60 lojas próprias e algumas franquias em todo país.

\subsection{Apresentação do caso da Empresa A}

\subsubsection{Evolução dos negócios da empresa na Internet}

Em 1995, o Grupo Supermercadista X lança no Brasil o sistema de supermercado virtual como uma tentativa de, através do uso da tecnologia, diminuir custos com infra-estrutura (imóveis, equipamentos, estacionamentos) e mão-de-obra, criando, assim, seu serviço de Delivery. No ano de 2000, o Grupo investe 4 milhões de dólares para integrar seus mais de 5.000 fornecedores através de uma rede de comunicação via Web-Business-to-Suplier, a qual permite troca de informações via Internet. Apropriando e integrando os conhecimentos do Delivery e do sistema de interface com fornecedores, é lançado em 2000 o site de varejo, dando início às atividades da Empresa A.

Desde sua criação, com a fundação da Empresa A, o site vem passando por algumas transformações, conforme vai aumentando a experiência e o contato da empresa com este tipo de atividade. Verificam-se três fases distintas na evolução do negócio desde sua criação até o período de 2001 após o boom das empresas ponto com. A Fase 1 caracteriza-se pelo foco no conteúdo, com a intenção de possibilitar aos clientes soluções para todas as suas necessidades, tais como: informações sobre saúde, nutrição, decoração da casa, turismo, lazer, moda, beleza, culinária, além de diversas outras dicas para facilitar a vida doméstica e social do usuário.

Durante a Fase 2 a empresa centra suas atenções no CE e na venda direta ao consumidor, causando uma mudança estrutural na Empresa A. O maior impacto verificado é a diminuição do 
quadro de funcionários, com redução entre 15 e $20 \%$, principalmente nos setores de Contabilidade, Financeiro, Pagamento e Tecnologia.

Já o foco da Fase 3 é o posicionamento da marca através do atendimento com rapidez e qualidade ao cliente. Investimentos altos em tecnologias avançadas têm como objetivo garantir ao usuário fácil acesso ao site, com navegação rápida e segura.

A trajetória trilhada através das transformações realizadas em cada uma das fases, trouxe um crescimento no volume de vendas. Entretanto, este aumento não foi suficiente para reverter os prejuízos financeiros ocorridos em todos os anos desde sua fundação. O ponto de equilíbrio calculado para o investimento ainda não havia sido atingido em 2001.

\subsubsection{Impactos da criação do CE na organização}

A Empresa A foi criada especialmente pelo Grupo Supermercadista X com o propósito de ser sua unidade de negócios de vendas virtuais. Em 2001, a Empresa A apresentava uma estrutura independente, apesar de compartilhar determinadas atividades com o Grupo X. As áreas exclusivas do Grupo Supermercadista X eram: atendimento ao consumidor, comercial, estocagem e distribuição. Já as áreas de compras/fornecedores corporativos, pesquisa em marketing corporativo, marketing corporativo, $\mathrm{RH}$ corporativo, logística corporativa, financeiro corporativo, cobrança/meios de pagamento, jurídico corporativo e tecnologia, eram de uso compartilhado. Nestes casos, a utilização da expressão "corporativo" caracteriza o compartilhamento de atividades dentro das unidades do Grupo Supermercadista X. Por fim, as áreas exclusivas da Empresa A eram: atendimento ao consumidor/telemarketing (venda e pósvenda), marketing, comercial, cadastro, estocagem/operações e tecnologia.

$\mathrm{O}$ atendimento ao consumidor/telemarketing (venda e pós-venda) prestava informações sobre produtos (preço, localização, formas de pagamento, etc.), realizava trocas de mercadorias, atendimento de reclamações, efetuava o contato com o cliente para verificar problemas na concessão de crédito, executava tele-vendas, fornecia informações quanto a pedidos efetuados (atendimento pós-venda), prestava auxílio sobre dúvidas de navegação no site da empresa, apoiava operações (crédito, operação e vendas) e encaminhava o consumidor para áreas específicas que pudessem responder às suas demandas.

A área de marketing era a responsável pela comunicação, promoção, divulgação e acordos com fornecedores (ações cooperadas). A área comercial responsabilizava-se pelas vendas, definição de preços, ofertas, merchandising, promoções e elaboração de calendário mensal e anual sobre ações de marketing e promoções. No setor de cadastro, os profissionais fotografavam os produtos, verificavam a existência de descrições técnicas definidas pelo próprio fornecedor ou as elaboravam quando as mesmas não eram fornecidas. $\mathrm{Na}$ estocagem/operações os pedidos eram recebidos, separados, acondicionados e processados, e a nota fiscal emitida. A distribuição ficava responsável por levar o produto até o consumidor final. Já a tecnologia ocupava-se dos sistemas de back office (atualizações de preços no site,etc.), sistemas de front office (operações do site e relações com os clientes), relações com a empresa que hospedava o site, monitoramento do site, aperfeiçoamento da funcionalidade e navegabilidade do site e acompanhamento do fluxo do pedido. 


\subsubsection{A integração de estruturas}

Verificou-se a sobreposição de atividades entre algumas atividades, especialmente em dois setores: (1) cobrança/meios de pagamento (de uso compartilhado) com o financeiro corporativo e (2) marketing corporativo com marketing da Empresa A. Apesar dessas sobreposições terem sido identificadas a empresa não havia tomado a iniciativa de unificá-las. A expectativa do gerente de operações da Empresa A na época era de que as áreas corporativas viriam a congregar estas atividades. Entretanto, era percebida uma leve resistência por parte da Empresa A em relação a este processo de incorporação e observava-se um jogo de poder, no qual a unificação implicaria uma perda de espaço e de autonomia da Empresa A. Esta perda de status pôde ser verificada principalmente na área de marketing.

A Empresa A tinha total autonomia sobre promoções, ações cooperadas com fornecedores, operadoras de cartão de crédito e portais, além de decisões sobre as ações de comunicação com os clientes. Naquele momento, temia-se que a unificação diminuisse a liberdade e a rapidez de resposta frente aos concorrentes, ou seja, uma das grandes vantagens de ser uma empresa exclusivamente virtual, baseada na interação direta com o cliente, poderia verse reduzida.

Em relação à incorporação da área de cobrança/meios de pagamento pelo financeiro corporativo, verificou-se preocupação quanto à forma como isso seria feito. As funções de cobrança e meios de pagamento virtuais e físicos eram bastante distintos, sendo considerados um ponto crítico em uma empresa virtual. Enquanto no supermercado o cliente está presente fisicamente, podendo ser realizada a conferência de crédito instantaneamente (seja através da análise de documentos e/ou acesso ao SPC-Serviço de Proteção ao Crédito), no mundo virtual o procedimento é muito mais criterioso, uma vez que não existe a presença física do comprador. A verificação do crédito implicava uma série de ações, muitas vezes realizadas manualmente, e contatos que envolviam operadoras de cartões de crédito e SERASA.

Em 2001, questionamentos do tipo "por que", "o quê" e, principalmente, "como" compartilhar atividades faziam parte das pautas de reuniões diárias estabelecidas entre o Grupo Supermercadista $X$ e a sua unidade de negócio de vendas virtuais. Já era percebida uma tendência de compartilhamento de funções. Segundo o gerente comercial da Empresa A na época a empresa utilizava uma parte própria e outra parte do grupo e estavam migrando tudo para o Grupo. Contudo, o grande desafio era superar o jogo de poder existente entre os envolvidos e as dificuldades inerentes a unificação.

O objetivo era a redução de custos, pois a estrutura do Grupo X estava instalada e operante. A grande questão era como a Empresa A poderia aproveitar melhor a infra-estrutura existente de modo a reduzir seus custos de operação e então obter vantagem competitiva diante da concorrência. Neste ponto residia um dos maiores benefícios advindos de modelos híbridos, os quais não caracterizavam empresas genuinamente virtuais: o aproveitamento da estrutura existente e a diluição dos custos operacionais do negócio. 


\subsection{Apresentação do caso da Empresa B}

\subsubsection{Evolução dos negócios da empresa na Internet}

A Empresa B, também atuante no setor supermercadista, possuía uma única unidade de vendas. A modalidade de vendas virtuais começou a ser cogitada no início de 1997. No entanto, as negociações para hospedagem e desenvolvimento da homepage da empresa começam apenas ao final do mesmo ano. Em abril de 1998 foi assinado o contrato e as atividades para implementar o projeto têm início, com conclusão e início das operações no final de 1998. Para que isso tenha sido possível, diversas atividades foram executadas previamente e as mais laboriosas foram a revisão e a uniformização da forma de cadastrar os produtos.

Com pouco mais de um ano de funcionamento a estrutura virtual, chamada de "Delivery", já superava seu ponto de equilíbrio e não constituía mais uma atividade deficitária, como era comum em empresas do gênero. Em 2001, o volume de vendas já representava 7,5\% do faturamento da empresa e os pedidos via Internet atingiam $40 \%$ do total com os demais $60 \%$ advindo de solicitações realizados por telefone (via 0800), utilizando o pessoal e a estrutura do Delivery. Outra curiosidade deste caso é a diferença do valor médio do ticket de vendas: no comércio eletrônico era quase oito vezes superior á média da loja física.

\subsubsection{Impactos da criação do CE na organização}

Em 2001, e mesmo quando da implantação das vendas virtuais, a estrutura organizacional da empresa era composta por direção geral e três gerências principais: comercial, administrativa e operacional. Com a entrada da empresa no $\mathrm{CE}$, foi acrescida a unidade de Delivery à estrutura organizacional existente, subordinada hierarquicamente à gerência operacional. As principais linhas de compartilhamento de atividades eram as estabelecidas entre o Delivery e os seguintes setores/áreas: setor financeiro da gerência administrativa; frente de caixa e SAC (serviço de atendimento ao cliente) da gerência operacional; e alimentos/linha seca, frios/laticínios/bebidas, hortifrutigranjeiros, e lanchonete/padaria/restaurante, da gerência comercial.

Além das áreas comerciais propriamente ditas, a gerência comercial agrupava também as atividades de recebimentos e informática, que tradicionalmente são funções administrativas. A área de informática prestava assessoria principalmente às unidades comerciais nos sistemas de cadastros de produtos e de informações de estoque, preços, volumes de vendas e compras. A área de recebimentos estava intimamente ligada às unidades comerciais, já que eram estas as unidades que negociavam com fornecedores e controlavam as entregas de mercadorias.

$\mathrm{Na}$ época da coleta de dados, a gerência de operações da Empresa B apoiava o processo de venda aos clientes e compreendia também o Delivery, segurança, frente de caixa e SAC. A gerência administrativa realizava atividades de apoio à empresa como um todo, incluindo o Delivery. As principais atividades desta gerência envolviam os setores de contabilidade, financeiro, jurídico e o centro de desenvolvimento de gestão, o qual se voltava às políticas de RH.

A unidade de Delivery estava estruturada em operações e entrega e inicialmente comportava apenas as operações de CE para vendas ao consumidor. O desenvolvimento desta atividade proporcionou bases para que outras iniciativas fossem empreendidas. A estrutura criada tanto para vendas pela Internet quanto para a entrega de produtos ao cliente permitiu que dois 
novos serviços fossem incorporados: vendas por telefone e entrega em domicílio do cliente de compras realizadas por ele próprio na loja física. Esta última atividade já era realizada pela empresa desde sua fundação. Até então, no entanto, se restringia às adjacências da loja onde auxiliares de caixa podiam chegar transportando mercadorias em carrinhos de supermercado. Com a inserção da modalidade Delivery tornou-se possível ampliar a área de abrangência de entregas através das vendas virtuais, expandindo, assim, a oferta dos serviços já prestados. Deste modo, as operações do Delivery compreendiam a comercialização de pedidos realizados via Internet e telefone, bem como atendimento ao cliente (reclamações, sugestões e pedidos de informações por $e$-mail). A entrega propriamente dita era efetuada por uma empresa terceirizada.

\subsubsection{A integração de estruturas}

A Empresa B procurou aproveitar ao máximo a estrutura, pessoas e capacidades existentes quando da criação da unidade de vendas eletrônicas. Com isso, diminuiu o volume de investimento necessário para empreender o projeto, aumentando o mínimo possível a estrutura geral da empresa. Conseqüentemente, custos e despesas fixas não tiveram aumento significativo, o que contribuiu para que se alcançasse com rapidez o ponto de equilíbrio das operações de vendas eletrônicas. Desta forma, atividades de suprimentos e vendas, como negociação com fornecedores, estoques, definição de preços, promoções e formas de pagamento, continuavam como competência da gerência comercial. Também a gerência administrativa estendeu suas responsabilidades para abranger a nova unidade de vendas virtuais. Isto explica por que o Delivery, embora compreendesse um processo de comercialização, encontrava-se alocado na gerência de operações. Na unidade virtual da Empresa B, restaram apenas funções operacionais, como cadastro de clientes, processamento de pedidos e entrega de mercadorias, ou seja, as atividades típicas e peculiares de venda virtual sem paralelo no processo de venda tradicional. A única atividade que apresentava sobreposição era o atendimento ao cliente. Sugestões, reclamações e pedidos de informações realizadas por telefone, ou presenciais, eram de responsabilidade do SAC (atividade da gerência operacional), enquanto as demandas recebidas por e-mail eram sanadas pelas operações do Delivery.

\subsection{Apresentação do caso da Empresa C}

\subsubsection{Evolução dos negócios da empresa na Internet}

Ao iniciar as atividades na Internet, em 1996, a Empresa C optou por não duplicar sua estrutura organizacional. Naquela época seus dirigentes já vislumbravam a Internet como sendo um canal adicional de distribuição, exigindo uma política comercial igual às demais lojas da rede de livrarias. Na corrente contrária ao boom das "ponto.com", no final da década de 90, mesmo tendo recebido diversas ofertas de aportes de capital, a Empresa $\mathrm{C}$ optou por continuar investindo no $\mathrm{CE}$ exclusivamente com capital próprio. $\mathrm{O}$ grupo empresarial tinha receio do surgimento de conflitos entre investidores com perfis e interesses diversos (sócios no negócio tradicional versus sócios no $\mathrm{CE}$ ). Apesar de resistir à criação de uma estrutura própria para atender ao $\mathrm{CE}$, a Empresa $\mathrm{C}$ acabou se rendendo e constituiu uma estrutura separada para a execução de atividades via Internet. A estrutura de CE possuía orçamento próprio e contava com 
aproximadamente 20 profissionais atuando exclusivamente em CE. Contudo, alguns recursos da empresa tradicional continuam a ser utilizados por essa nova estrutura.

Em 1996 era comum encontrar negócios eletrônicos vinculados a grandes portais. Seguindo esta "garantia de sucesso", a Empresa C, até meados de 2000, se manteve vinculada a uma série de grandes portais. Porém, notou que $80 \%$ das vendas eram realizadas pelo site da empresa, resultante de acessos realizados através da digitação do nome da loja. Então, a partir de 2000, a empresa inicia uma redução gradual de vinculação nesse meio, não renovando mais os contratos existentes. Tal medida se mostrou precursora como comprovou pesquisa pela E-BIT (2006b), demonstrando que apenas $9 \%$ das compras são oriundas de cliques em banners em outro site da Internet.

$\mathrm{Na}$ guerra das "ponto.com", o que realmente tornava acirrada a disputa no CE era a política comercial diferenciada entre as operações tradicionais e as virtuais. Muitos concorrentes da Empresa C, inclusive ela própria, ofereciam grandes descontos, muitas vezes irreais e insustentáveis no mercado livreiro, já que eram as próprias editoras que estabeleciam os preços e não as livrarias. Esta política diferenciada gerava desconforto entre os clientes e muitos ficavam insatisfeitos em pagar um valor maior na loja, quando o valor do mesmo produto adquirido no site era muitas vezes menor. Além disto, havia por parte do cliente da Empresa $\mathrm{C}$ a percepção de estar arcando com o custo de deslocamento e estacionamento.

\subsubsection{Impactos da criação do CE na organização}

Em meados do ano 2000, a Empresa $\mathrm{C}$ decidiu tomar uma atitude drástica, contrária às práticas de seus concorrentes: estabelecer uma política única de preços para a "ponto.com" e para as lojas. Desta forma, acabou com a diferença de preços, voltando a tratar as transações de CE como mais um canal de distribuição, tal como no inicio de suas atividades na Internet. Também nesse período, ao mesmo tempo em que constatava não ser o mercado de CE tão significativo como se imaginava, a estrutura de vendas via Internet da Empresa C começa a ser enxugada, voltando a ser praticamente a mesma quando do início em 1996.

As atividades de apoio e compras voltaram a ser compartilhadas com as existentes nas operações tradicionais. As únicas atividades que mantinham uma estrutura diferenciada eram: entrega, atendimento ao cliente e marketing. Na época, havia uma forte tendência à integração das atividades de marketing, sendo que algumas atividades já vinham sendo desenvolvidas com o esse objetivo. Assim, nesse período, o call center da Empresa $\mathrm{C}$ foi reformulado objetivando melhorar a qualidade do atendimento e o quadro de funcionários enxugado, investindo-se em capacitação para os que ficaram. Tais ações começaram a surtir resultado e em setembro de 2001 a revista Negócios Exame verificou um aumento na satisfação dos clientes da Empresa C no requisito "atendimento ao cliente pela Internet" e também "por telefone".

\subsubsection{A integração de estruturas}

Em 2001, o CE da Empresa C não possuía estoque, sendo feito um cross doc para as livrarias. Isso significava que, apesar do depósito ser o mesmo para ambos os canais, uma área no depósito era dedicada para atender exclusivamente os pedidos de CE (inclusive com embalagem diferenciada). Embora com espaços de estocagem distintos, a área de recebimento de mercadorias era a mesma. 
Os pedidos das lojas e do $\mathrm{CE}$ eram realizados em conjunto, através de um único relacionamento com seus fornecedores. A geração de pedidos era realizada todas as manhãs, com base no conjunto total de requisições do dia anterior. Logo que as mercadorias chegavam ao depósito geral eram separadas em quatro grupos: CE, lojas (especificada a localidade), cliente (loja em que será retirada a mercadoria) e venda para terceiros (universidades, outras livraria, etc.).

Também era dada prioridade de atendimento aos clientes do CE, já que existia uma expectativa deste consumidor em relação à agilidade na entrega de mercadorias dentro do dia e hora agendados. Ou seja, caso um determinado livro tivesse sido adquirido pela loja, e entre a realização do pedido e a entrega da mercadoria pelo fornecedor a empresa recebesse um outro pedido deste mesmo livro, era atribuído prioridade ao pedido realizado via Internet.

Inicialmente, esta política de estocagem e distribuição criava diversos conflitos entre as lojas e os responsáveis pelo CE. A percepção das lojas, para esta nova modalidade de venda, era de que havia uma "concorrente dentro de casa", pois além de terem prioridade na distribuição possuiam preços diferenciados. Contudo, a partir do estabelecimento de uma política comercial integrada, em meados de 2000, esse relacionamento se altera positivamente, tendo-se inclusive realizado promoções conjuntas. O chamado "bônus cruzado" era um exemplo do ganho adquirido com tal integração, proporcionando descontos para clientes que adquirissem em uma ou em outra modalidade.

Com o enxugamento realizado no orçamento de marketing da Empresa $\mathrm{C}$, ocorrido em meados de 2000, restaram ações que não possuíam custo elevado. Uma delas era o chamado "marketing comercial", identificado pelos entrevistados como um diferencial em relação à concorrência. Esta sistemática consistia na remessa de comunicações regulares para o cliente cadastrado na Internet (promoções, sugestões, lançamentos, etc.).

Outro projeto promissor a época era o acesso ao CE da Empresa $\mathrm{C}$ de dentro de suas próprias lojas. A idéia era criar o hábito de comprar via Internet entre os clientes da empresa. É preciso lembrar que em 2001, poucas eram as pessoas que tinham acesso fácil à Internet e menos ainda eram as que costumavam realizar compras via Web (E-BIT, 2006a). Além de otimizar os esforços dos diferentes canais, focalizando em um único cliente, objetivava-se substituir o serviço de entrega regional das lojas (encomenda) pela entrega via Internet, já que estes processos são realizados em paralelo. Para possibilitar a implementação deste serviço, investimentos altos em TI teriam que ser realizados, fato que não se concretizou por completo.

O superávit nas atividades de $\mathrm{CE}$, embora pequeno, somente foi obtido após cinco anos de atuação. Em 2001, apesar do volume de vendas via Internet ter se reduzido em torno de 60\%, a lucratividade não diminuiu, principalmente devido à sinergia criada e ao compartilhamento entre os canais de venda tradicional e virtual.

\subsection{Análise dos Casos à Luz dos Modelos Teóricos}

Nesta seção os três casos anteriormente descritos são analisados sob a ótica do modelo de PORTER (2001) e de VASCONCELlOS et al. (2004). Também são realizadas análises comparativas de modo a ilustrar o objetivo principal deste artigo: o pioneirismo no processo de adoção do CE por empresas varejistas brasileiras. 


\subsubsection{Análise pelas forças competitivas}

\subsubsection{Barreiras à entrada}

Nos três casos estudados realizaram-se investimentos em TI para possibilitar a implementação do CE. Em alguns casos, estes investimentos não se restringiam exclusivamente à TI. Dependendo da visibilidade desejada pela empresa, foram necessários grandes dispêndios em marketing, como no caso da Empresa A. Isto se deveu à estratégia de criar uma estrutura separada e diferenciada da existente. A Empresa C também promoveu investimentos em TI e marketing, contudo, em menor monta, pois houve o aproveitamento de parte da infra-estrutura existente, o que lhe permitiu alcançar em cinco anos o ponto de equilíbrio. Já na Empresa B, por atuar em uma área de abrangência menor que as Empresas $\mathrm{A}$ e $\mathrm{C}$ (apenas sua cidade e arredores), os investimentos ocorreram em menor volume.

Assim, no que se refere às barreiras de entrada, percebeu-se que apesar de existir uma facilidade tecnológica, com custos decrescentes para implementação de CE, o fato de se estabelecer um site não foi suficiente. Aportes financeiros em marketing foram necessários, principalmente quando o público que se queria atingir estava geograficamente distribuído. Se por um lado a força de vendas na loja física é reduzida, por outro lado foram necessários grandes investimentos em logística e no desenvolvimento de relacionamentos permanentes com os clientes.

\subsubsection{Fornecedores}

A negociação com fornecedores nos três casos foi, desde o início das operações, de forma compartilhada entre as unidades virtuais e tradicionais. A razão parece ser óbvia: aumentar o poder de barganha. Tanto no mercado supermercadista quanto no livreiro a faixa de negociação é muito restrita e a maioria dos produtos possui valores praticamente "tabelados" pelos seus fornecedores. Considerando que as empresas aqui estudadas atuam exclusivamente no varejo e seus fornecedores, em sua grande maioria, não costumam realizar vendas diretas aos consumidores, a proposição de Porter de excluir um canal de distribuição não se aplica.

Além disto, os três varejistas contaram com um aliado forte: o poder de penetração de suas marcas nas regiões onde atuavam. Neste sentido, a questão da distribuição deve ser ressaltada entre estes casos. Nas Empresas A e B, as entregas restringiam-se às cidades onde suas lojas estão localizadas. Já as entregas da Empresa C podiam ser realizadas em todo o território nacional e no exterior. Isso se deve, principalmente, ao tipo de produtos comercializados por estas empresas. No setor supermercadista, grande parte dos produtos são perecíveis e de grande volume, dificultando entregas muito distantes. No entanto, os produtos comercializados pela Empresa C, em sua maioria livros, são facilmente transportados, podendo realizar entregas inclusive no exterior.

\subsubsection{Rivalidade entre concorrentes}

Logo no início do boom da Internet, quando as empresas em análise iniciaram suas atividades virtuais, existia a crença de que não estar na Internet significava estar fora do mercado. Contudo, esta imagem distorcida foi superada pela necessidade de suprir as reais demandas dos clientes. Manter um site não se constituía em problema, pois ele podia ser 
meramente informativo. Mas, para realmente fazer parte deste "mercado", era preciso interagir apropriadamente. Assim, questões como logística e relacionamento com clientes fizeram parte da pauta de discussões das empresas estudadas, as quais vislumbravam a Internet não como um novo mercado, mas como mais um canal de vendas e relacionamento. Mesmo a grande a concorrência por preços durante as primeiras fases de criação dos negócios virtuais (vide, por exemplo, o caso da Empresa $\mathrm{C}$ não cobrando frete para entrega), ao contrário do que afirma Porter, a competição não se estabeleceu ao nível de preços e sim mediante os serviços prestados por estas organizações. O tipo de relacionamento mantido com o cliente, o cumprimento nos prazos de entrega, serviços complementares, valor das taxas de entrega/frete, foram considerados os diferenciais competitivos em relação aos concorrentes.

\subsubsection{Produtos substitutos}

As ameaças de entrada de novos produtos e serviços substitutos apresentadas no modelo de Porter pareceram não afetar os casos estudados neste trabalho. O que se pode considerar como "produto substituto" para a Empresa C, por exemplo, são os e-books. Contudo, ainda hoje estes não parecem ter alcançado a preferência do público, mesmo porque muitas das tecnologias que facilitam a leitura deste tipo de produto são pouco acessíveis aos consumidores brasileiros. No caso das Empresas A e B (e também para a Empresa C), é possível imaginar que os fornecedores possam atingir seus clientes finais diretamente. Contudo, não parece haver tendência nem disponibilidade destes para ampliar o seu leque de ações. O foco no core business ainda é predominante entre as indústrias dos fornecedores e relacionar-se comercialmente com clientes finais não parece estar entre suas prioridades.

\subsubsection{Clientes}

Nas empresas pesquisadas não são percebidas possibilidades de barganha pelos clientes. O que ocorre, muitas vezes, é o acesso a promoções diferenciadas entre as lojas virtuais e as tradicionais. Talvez estas promoções possam ser consideradas formas de barganha, já que existe uma vantagem financeira em utilizar a modalidade.

\subsection{Análise pelos níveis de compartilhamento organizacional}

Para examinar de forma apropriada os casos através do modelo desenvolvido por VASCONCELLOS et al. (2004) e utilizado por seus colegas (2005a; 2005b), realiza-se a análise separadamente por empresa. Ao final, apresenta-se um quadro comparativo.

\subsubsection{Empresa A}

Este caso pode ser analisado em três diferentes fases. A primeira se verifica já no surgimento da Empresa A, a qual nasce totalmente separada do Grupo X, com uma forte preocupação em oferecer conteúdo específico para seus clientes. Nesta fase, pode-se afirmar que se encontrava no nível 1 do modelo, já que não existia nenhum compartilhamento de recursos de infra-estrutura e os recursos eram duplicados existindo uma estrutura única para a Empresa A. A segunda fase caracterizou-se por uma intensificação no $\mathrm{CE}$, através da venda direta ao consumidor e posicionamento da marca no CE. Neste ponto, verificou-se o nível 2 do modelo em 
questão, em que alguns recursos de infra-estrutura foram compartilhados e perdurou até o período delimitado de análise, ano de 2001. Logo em seguida, o Grupo X extinguiu a Empresa A para somente posteriormente retomar as atividades de comércio eletrônico.

\subsubsection{Empresa B}

A estrutura organizacional da Empresa B era bastante simplificada desde o início de suas atividades, sem grandes incorporações estruturais. Assim sendo, é possível constatar que ela já começa no nível 3 deste modelo, compartilhando todos os seus recursos de infra-estrutura, até se aproximar rapidamente do nível 4. Isso permitiu uma operação virtual com custos reduzidos, tendo-se adicionado basicamente custos variáveis às atividades, o que contribui para que a empresa alcançasse de forma precoce o equilíbrio financeiro nas atividades de comércio eletrônico.

\subsubsection{Empresa C}

Ao analisar-se caso da Empresa C, observa-se que esta passou por idas e vindas, diferentemente das demais. Ao iniciar suas atividades de forma gradual, compartilhando grande parte de seus recursos de infra-estrutura, considera-se que iniciou no nível 3 do modelo. Contudo, com o ímpeto de crescimento em $\mathrm{CE}$, alavancado em parte pela pressão da concorrência e exigência dos consumidores, foram separadas grande parte de suas operações. Assim, ela passa para o nível 2 e limiar do nível 1, pois alguns poucos recursos eram compartilhados. Depois de algum tempo, especialmente em função da dificuldade de alcançar o ponto de equilíbrio, a empresa volta a compartilhar recursos e a vislumbrar o CE como mais um canal de vendas, retornando ao nível 3 deste modelo e direcionando-se ao nível 4.

\begin{tabular}{|l|c|}
\hline Empresa & Nível de compartilhamento do CE no tempo \\
\hline $\mathrm{A}$ & Nível $1 \rightarrow$ Nível 2 \\
\hline $\mathrm{B}$ & Nível $3 \rightarrow$ Nível 3 (quase 4) \\
\hline $\mathrm{C}$ & Nível $3 \rightarrow$ Nível 2 (quase 1) $\rightarrow$ Nível 3 \\
\hline
\end{tabular}

Quadro 1: Nível de compartilhamento x Estudos de Caso

Fonte: dados do estudo

Desta forma, os casos das empresas B e C aqui estudadas antecipam os resultados obtidos por empresas estudadas posteriormente por VASCONCELlOS e MURITIBA (2005c), os quais aplicaram este mesmo modelo em 26 empresas e observaram que a grande maioria delas $(81 \%)$ concentrou-se nos níveis 3 e 4.

Interessante também examinar a diferença no nível de compartilhamento entre os casos estudados. Apesar de todas terem iniciado suas atividades de CE na mesma época, na segunda metade da década de 1990, pressupostos diferentes guiaram suas estratégias. O Grupo X abre uma empresa exclusivamente para $\mathrm{CE}$; a Empresa B, desde seus primórdios, compartilha infraestrutura; a Empresa $C$, numa seqüência de avanços e retrocessos, compartilha os recursos organizacionais. 


\subsection{Principais Desafios e Oportunidades nas Empresas Pioneiras}

A necessidade de evolução dos meios de pagamento merece destaque. Neste sentido, a integração e o aperfeiçoamento dos sistemas entre operadoras de cartão de crédito, bancos, lojas e outras empresas prestadoras de informações, além de proporcionar maior segurança ao usuário e às empresas, proporcionou maior agilidade na verificação do crédito e maior rapidez na efetivação do serviço. O desenvolvimento de sistemas de comunicação entre a loja e o serviço de transporte do produto até o destino final, de gerenciamento dos estoques e a apresentação dos produtos no site (responsabilidade da área de cadastro) são pontos que também mereceram atenção especial, pois são atividades que permite alcançar diferencial no desempenho do negócio virtual. Desta forma, a necessidade de se reconhecer e respeitar as especificidades do mundo virtual foi um aspecto fundamental na utilização do CE e ocorreu nas três empresas estudas

Esse desafio ainda persiste: transformar "bits" em "átomos" (NEGROPONTE, 1995). Receber os pedidos é tecnologicamente simples - é questão de investimento em TI -, mas fazer com que a mercadoria desejada chegue ao consumidor oportunamente ainda é um desafio. Entende-se que a logística de produtos ofertados em um supermercado é mais complexa que a de uma livraria, mas ambas precisam fazer com que o consumidor receba a mercadoria dentro do prazo combinado e em condições adequadas de uso.

... é o famoso trio pick, pack, delivery, que é a seleção dos produtos, embalagem e entrega. No mundo tangível essas atividades são feitas pelo cliente, que percorre as gôndolas, seleciona, pega, coloca no carrinho, leva até o caixa e lá trata de colocar nos saquinhos e depois transportar até sua casa imediatamente após a compra. Um supermercado que venda pela Internet precisa ter funcionários selecionando e coletando os produtos, embalando de uma forma mais cuidadosa e cara do que o simples saquinho e fazendo um transporte que, por não ser imediato, precisa ser feito em veículos especialmente adaptados para transportar separadamente itens congelados, frios e em temperatura ambiente (PERSONA, 2006).

A Empresa C, por exemplo, ao realizar uma análise de rentabilidade de sua estrutura de $\mathrm{CE}$, conclui que este tipo de operação não possuía custos baixos, ao contrário do que imaginava em um primeiro momento. Os custos de TI necessários para se ter um site eficiente e eficaz para a realização de atividades de CE foram bastante elevados. Da mesma forma, a sua manutenção e a dos profissionais envolvidos também foi mais cara que a de uma loja tradicional. O seguinte trecho retirado de uma das entrevistas ilustra bem este raciocínio:

Gasta-se mais tempo para atender o cliente via Web. Se o cliente envia o pedido e não se tem no estoque a gente é que fica com o 'pepino' de ter que consegui-lo, a busca é transferida para nós. Se ele não acha na loja, dificilmente ele encomenda, ele vai na loja do lado e tenta achar o livro. Isso requer mais gente trabalhando. A rentabilidade somente ficará maior em uma loja maior que tenha mais volume. Enfim, a venda na Internet é mais cara que na loja.

Tal custo elevado pôde ser verificado no caso da Empresa A que encerrou atividades ao final de período de análise desse estudo, em virtude de prejuízos acumulados e crescentes ano a ano com a operação virtual.

Outro aspecto característico daquelas empresas que iniciam atuação no CE referiu-se ao uso da Internet como um novo canal de comunicação com seus clientes. Devido as suas características, a utilização da Internet estava e ainda permanece inclusa nos planos de marketing de diversas empresas com o intuito de divulgar, informar, ampliar a rede de comunicações e, principalmente, atingir o maior número de consumidores e potenciais consumidores para 
aumentar as vendas, a visibilidade e a credibilidade da empresa, embora o canal mais popular no Brasil ainda seja a televisão (E-BIT, 2005, p.27).

Essa orientação para a comunicação com clientes esteve presente fortemente nos casos das Empresas A e C, que consideravam a internet e o comércio eletrônico estratégicos para o posicionamento futuro dos empreendimentos. A iniciativa de virtualizar a comercialização estava associada no curto prazo a um novo canal de comunicação com os clientes e no longo prazo a uma nova forma de fazer negócios de forma lucrativa, embora em uma posição futura incerta que não se sabia quando ocorreria, mas se acreditava que mais cedo ou tarde viria. Estas duas empresas parecem ter compartilhado uma visão de que deveriam estar na Internet independentemente da incerteza quanto ao ponto em que as atividades se tornariam lucrativas e que o futuro compensaria o presente. Postura esta que se aproxima mais de uma crença do que de uma visão estrategicamente pensada.

Vale notar que as empresas A e C conceberam suas operações em comércio eletrônico como um novo negócio que se diferenciava do tradicional. A Empresa A é criada pelo Grupo Supermercadista X para atuar apenas na Internet com atividades e operações próprias de forma similar a uma estratégia corporativa de diversificação relacionada. A Empresa $\mathrm{C}$ criou um canal de comércio eletrônico em sua estrutura interna que, se no início estava mais integrada às demais operações, em seguida assumiu maior autonomia afastando-se das atividades já desenvolvidas no comércio de lojas físicas. Enquanto a Empresa A manteve essa característica de independência maior, a Empresa C, a partir de 2000, reiniciou a integração das atividades virtuais com as de venda física.

De forma diversa, a Empresa $\mathrm{B}$ concebeu suas atividades de comércio eletrônico majoritariamente como um canal de venda com seus clientes atuais e potenciais. O negócio virtual nunca esteve dissociado das operações do negócio físico e foi concebido com um completo de sua atuação no mercado. É curioso notar que a denominação de Delivery utilizada para o comércio eletrônico faz referência justamente à parte tangível do negócio que é a entrega. Desde o surgimento, a Empresa B optou pela maior integração possível de estruturas, criando apenas aquelas indispensáveis para iniciar as vendas virtuais e aproveitando ao máximo as operações existentes.

Assim, diante da situação atual das empresas analisadas, parece não haver maior dúvida que o compartilhamento máximo de recursos de infra-estrutura e informacionais foram vitais para o sucesso de empreendimentos para superar o ponto de equilíbrio em atividades de CE. A Empresa B apresentou maior consistência no esforço de integração e alcançou logo o ponto de equilíbrio, a Empresa $\mathrm{C}$ passou a obter resultados melhores quanto retomou a iniciativa original de integração de estruturas, e, por fim, a Empresa A, manteve os negócios com maior grau de dissociação e encerrou as atividades logo após o período analisado.

Conforme os entrevistados da Empresa B, o conceito de "Shopping Virtual", através de um grande portal, não deu certo na Internet. Nesse sentido, ressalta-se a ausência da interação social nesta modalidade. Para eles, as pessoas têm necessidade de tomar como referência uma Brick \& Mortar para realizar suas compras. O consumidor necessita sentir confiança em uma marca que possua uma estrutura física, pois, caso ocorra algum problema, ele pode "bater na porta" da loja. Além do mais, os entrevistados acreditavam que as vendas pela Internet ocorriam por necessidade e não por impulso, como em um shopping center tradicional, e por este motivo a 
Internet comercial devia ser encarada como um canal complementar de vendas e não como um único canal. Daí a conclusão de que a integração era essencial para o sucesso do empreendimento.

\section{CONSIDERAÇÕES FINAIS}

O objetivo deste estudo foi investigar o pioneirismo no processo de adoção de CE por empresas varejistas brasileiras. A compreensão sobre como algumas empresas brasileiras, já atuantes no varejo tradicional, iniciam e desenvolvem seus negócios através deste novo ambiente empresarial, permite a "pragmáticos", "conservadores" e "céticos" se estabelecerem no "mercado desenvolvido", como hoje pode ser considerado o CE (MOORE, 1996).

Ainda não existem pesquisas suficientes que apontem para alternativas concretas em relação aos processos de encontro dos mundos real e virtual no negócio das organizações. A explicação está na pouca experiência das empresas neste sentido, o que dificulta a visualização do impacto das ações tanto para o lado da virtualização quanto o da desvirtualização. O aprender na prática é um processo rico, mas às vezes extremamente arriscado, principalmente num mercado que não admite erros. Mas o que aprender sobre o confronto dos dois mundos? Antes de tudo, sua complexidade e a necessidade de geração de alternativas de ações das empresas para potencializar os negócios do mundo virtual.

A contribuição do presente estudo consiste principalmente em ressaltar alguns pontos considerados críticos que envolvem as operações do mundo virtual entre os pioneiros e que podem impactar os negócios no momento presente. Os movimentos de integração das atividades virtuais e não virtuais parecem ser uma tendência irreversível, até que o equilíbrio seja alcançado. Os casos analisados ressaltam a importância dessa integração e a necessidade de conceber o comércio eletrônico como um negócio e não como uma idealização da uma atividade desejada.

A investigação, mesmo mostrando os processos diferenciados pelos quais cada empresa passou e a forma como vislumbrou o $\mathrm{CE}$, conduz à mesma conclusão: o $\mathrm{CE}$ é mais um novo canal de distribuição e de negócios com o cliente final e aqueles que antes perceberam isso obtiveram melhores resultados. Em decorrência desta afirmação e diante do conteúdo analisado, pode-se afirmar que o CE se justifica, uma vez que as empresas em estudo continuam - mesmo que de forma diferenciada em relação ao início - mantendo atividades de CE.

No que se refere às limitações deste estudo, ressalta-se a impossibilidade de generalização quando utilizado o método do estudo de caso e de cunho exploratório. Desta forma recomenda-se que outros estudos acerca do pioneirismo de empresas varejistas brasileiras no comércio eletrônico com clientes finais sejam realizados. Considerando que este estudo estudou a ação de empresas tradicionais pioneiras que iniciaram atividades virtuais cabe sugerir a investigação desse fenômeno em empresas que iniciaram puramente como negócios eletrônicos e depois adotaram atividades típicas de negócios físicos. 


\section{REFERÊNCIAS}

Aktouf, O. Governança e Pensamento Estratégico: uma crítica a Michael Porter. Revista de Administração de Empresas (RAE), v.42, n.3, p.43-53, Jul/Set. 2002.

Branski, R.M. Desafios da Venda Direta ao Consumidor pela Internet. In: SiLVEIRA, J.A.; ÂNGElo, C.F. (Orgs.). Varejo Competitivo, São Paulo: Atlas, 2000.

Chahin, A. et al. (Orgs.). E-gov.br: a próxima revolução brasileira. São Paulo: Prentice Hall, 2004.

Comscore Networks. ComScore Networks Reports Total Non-Travel E-Commerce Spending Reaches \$102 Billion in 2006. 03 Janeiro 2007. Disponível em: < http://www.comscore.com/press/release.asp?id=1166 >. Acesso em: 09 mai. 07.

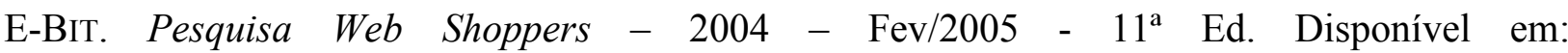

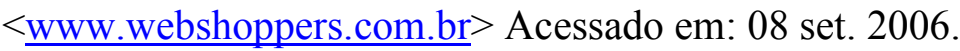

E-BIT. Pesquisa Web Shoppers - Relatório $1^{\mathrm{o}}$ Sem./2006a - 14 ${ }^{\mathrm{a}}$ Ed.. Disponível em: <www.webshoppers.com.br > Acesso em: 07 set. 2006.

E-BIT. Pesquisa Web Shoppers - 2005 - Jan/2006b - 13 ${ }^{\mathrm{a}}$ Ed. Disponível em: <www.webshoppers.com.br > Acesso em: 12 fev. 2006.

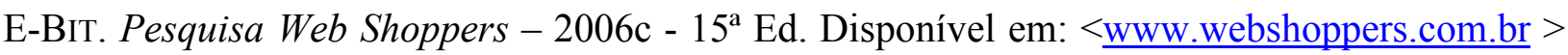
Acesso em: 9 mai. 2007.

FERrer, F.; Santos, P. (Orgs.). E-Goverment: o governo eletrônico no Brasil. São Paulo: Saraiva. 2004.

Kalakota, R.; Robinson, M. E-business 2.0: roadmap for success. New York: AddisonWesley, 2001.

Moore, G. Dentro do Furacão: estratégias de marketing para empresas de ponta. São Paulo: Futura, 1996.

MYER, W. H. The 2000 Internet survey. Mortgage Kanking, Washington, Oct., p. 42-53, 2000.

Negroponte, N. A Vida Digital. São Paulo: Companhia das Letras, 1995.

Persona, M. Para onde vai o comércio na Internet? Disponível em: < http://www.mariopersona.com.br/entrevista varejo.html> Acesso em: 08 set. 2006.

Porter, M. Strategy and the Internet. Harvard Business Review, p. 62-78, Mar. 2001.

Selltiz, C. et al. Métodos de pesquisa nas relações sociais. São Paulo: Pedagógica e Universitária, 1974.

Turban, E.; LeE, J.; KIng, T.; Chung, H.M. Electronic commerce: a managerial perspective. New Jersey: Prentice Hall, 1999.

VAsconcellos, E. (Org.). e-Commerce nas Empresas Brasileiras. São Paulo: Atlas, 2005a.

VAsconcellos, E. (Org.). Competitividade e Negócios Eletrônicos: Experiências de Empresas Brasileiras. São Paulo: Atlas, 2005b. 
Vasconcellos, E.; Muritiba, S. Estrutura Organizacional como Diferencial Competitivo em Negócios Eletrônicos: O Caso Solidez-Investware. In: VAsconcellos, E. (Org.). Competitividade e Negócios Eletrônicos: Experiências de Empresas Brasileiras. São Paulo: Atlas, 2005c.

Vasconcellos, E. P. G. ; Muritiba, S.N.; Zilber, S.N.; Ozaki, A.M. Arquiteturas Organizacionais para implantação de E-Business. In: Sbragia, R.; GalinA, S. V. R. (Orgs.). Gestão da Inovação no Setor de Telecomunicações. 1 ed. São Paulo: PGT/USP, p.231-263, 2004.

YIN, R. Case Study Research: design and methods. London: Sage, 1994. 